\title{
Atom-probe study Ti Al based alloy
}

\author{
A. HUGUET, A. MENAND, A. DENQUIN* and S. NAKA* \\ Laboratoire de Microscopie Ionique, UA 808 du CNRS, Faculté des Sciences, BP. 118, 76134 Mont Saint \\ Aignan, France \\ ' Office National d'Etudes et de Recherches Aerospatiales, BP. 72, 92355 Châtillon, France
}

\begin{abstract}
Two phase $\alpha_{2}+\gamma \mathrm{Ti}$ Al based alloys have a better ductility than single phase alloys. Oxygen seems to have a key role with respect to the ductility properties of these alloys. This paper present an atom probe determination of oxygen concentration in $\alpha_{2}$ and $\gamma$ phases of two phase alloys and in single phase alloys. The nearly constant observed oxygen concentration in $\gamma$ phase is considered as the oxygen maximum solubility in this phase $(\sim 200$ at. $\mathrm{ppm})$. The oxygen excess which exists in normal alloys either leads to an oxide precipitation in single phase alloys or is absorbed in the $\alpha_{2}$ phase of two phase alloys. The absence of oxides in two phase alloys could explain the better ductility of these alloys.
\end{abstract}

\section{INTRODUCTION}

The first atom probe study of titanium based alloys was performed in 1986 (1). This technique, well adapted to study decomposition phenomena in alloys at an atomic scale, has been successfully used for instance to characterise GP zones in $\mathrm{Ti}_{3} \mathrm{Cu}$ or to investigate the isothermal $\omega$ phase precipitation in Ti$10 \mathrm{~V}-2 \mathrm{Fe}-3 \mathrm{Al}(2)$

A new type of titanium base alloy, titanium aluminides based on $\mathrm{Ti} \mathrm{Al}$, is now receiving an increasing attention because of the low density and attractive properties at high temperature of such alloys (high mechanical strength and good oxidation resistance). However these alloys suffer from a low ductility up to about $600^{\circ} \mathrm{C}$ which limits their application. As compared to the single phase $\gamma$ alloys, two phase $\alpha_{2}+$ $\gamma \mathrm{Ti}$ Al base alloys exhibit a higher ductility (3) (4). Several mechanism have been proposed to explain this ductility improvement (5). Amongst the possible explanations two different effects have been mainly considered : a microstructural effect and a purification effect of the $\gamma$ phase from interstitial elements. In the first case it has been suggested that the lamellar structure of the $\alpha_{2}+\gamma$ alloys improves ductility by inducing fine uniform deformation of $\gamma$ plates in the early stage of deformation and then $\alpha_{2}$ in the latter stage (3), the FIM image of a specimen tip for a two-phase alloy, shown in Fig. 1, clearly exhibits the lamellar microstructure of such alloys. The second hypothesis is that $\alpha_{2}$ phase enhances ductility of alloys by scavenging interstitial impurities (namely oxygen). This lowers the interstitial level in the $\gamma$ phase, leading to a change in deformation mechanism (6).

This scavenging effect of oxygen by the $\alpha_{2}$ phase has been recently clearly shown by atom probe studies (7) (8), see also Fig. 2 . However the raison for the ductility improvement does not seem to be only due to a simple purification effect of the $\gamma$ phase (8). From this point of view it is of the utmost 
importance to determine the oxygen level in the $\gamma$ phase with a sufficient accuracy. The present paper report the composition of $\alpha_{2}$ and $\gamma$ phases (with particular emphasis on oxygen concentration) as measured by AP analysis of two-phase alloys and single-phase alloys with different oxygen nominal concentrations. The results are discussed as regard to a possible explanation for the ductility improvement of the two-phase TiAl alloys.

\section{EXPERIMENTAL PROCEDURE}

The present study was carried out on two binary two-phase alloys $\mathrm{Ti}_{52} \mathrm{Al}_{48}$ and $\mathrm{Ti}_{54} \mathrm{Al}_{46}$ of the normal impurity level $(\approx 2500$ at. ppm $\mathrm{O})$ and on $\gamma$ single-phase alloy $\mathrm{Ti}_{48} \mathrm{Al}_{52}$ highly purified (700 at. ppm 0 ) or oxygen charged ( 1 at $\%$ and 2 at $\%$ ). TEM observations were performed on a JEOL $200 \mathrm{CX}$. Finely sharpened needle-like sample for AP-FIM examinations were prepared by electropolishing techniques described elsewhere(9). In order to determine the oxygen content in the $\alpha_{2}$ and $\gamma$ phases with a good accuracy, a high resolution energy compensated atom probe (10) was used for analysis. The optimum experimental conditions are the following : a tip temperature of $50 \mathrm{~K}$, a pulse fraction of $19 \%$ and a vacuum of a few $10^{-10}$ Torr during analysis.

Atom probe analyses reveal the presence of a surface oxide layer . This oxide layer is present on both $\alpha_{2}$ and $\gamma$ phases (Fig. 2). This oxide layer forms in the atom probe even in good vacuum conditions after a few ten minutes and exceed a monolayer after a few hours. Such an oxide layer can easily be removed in the atom probe by field evaporation.

Mass spectra obtained after a removal of surface oxide layer are shown (fig. 3) for the two $\alpha_{2}$ and $\gamma$ phases. Both titanium and aluminium atoms are mainly detected as doubly charged ions. The proportion of minor $\mathrm{Ti}^{3+}$ and $\mathrm{Al}^{3+}$ detected ions is higher in $\alpha_{2}$ phase than in $\gamma$ phase. This indicates that the evaporation field is in average higher for $\alpha_{2}$ phase. Mass spectra also reveal the presence of molecular $(\mathrm{TiO})^{2+}$ ions. Those ions coming from $\alpha_{2}$ phase are numerous whereas those originating from $\gamma$ are in very small amount. The possible detection of oxygen as $\mathrm{O}^{+}$at $16 \mathrm{amu}$ should also be considered. This is fairly complex due to the fact that a fraction of titanium detected as $\mathrm{Ti}^{3+}$ gives for the main isotope ${ }^{48} \mathrm{Ti}^{3+}$ the same value of $16 \mathrm{amu}$. The presence or not of a noticeable fraction of oxygen as $\mathrm{O}^{+}$is therefore a crucial issue in the quantitative analysis of the oxygen concentration particularly for $\gamma$ phase analysis where the oxygen level is very low. By careful measurements of the isotopic proportion in the $\mathrm{Ti}^{3+}$ peaks it is possible to answer this question. As the evaporation field conditions are not the same for $\alpha_{2}$ and $\gamma$ these measurements have been made from the results obtained on the $\gamma$ phase itself. The results we obtained show that the 16 peak may be considered as mainly composed of ${ }^{48} \mathrm{Ti}^{3+}$. In this 16 amu peak, a maximum of 30 at.ppm (taking a $2.5 \%$ statistical risk) may be considered as oxygen ions, whereas the oxygen level obtained from the $(\mathrm{TiO})^{2+}$ number of ions is in the range $150-250 \mathrm{ppm}$.

For such a low concentration, it is also necessary to evaluate the background noise, in order to insure the quantitativity of the oxygen and Carbon measurements. This has be done for instance for oxygen by taking a mass interval of $2 \mathrm{amu}$ between 33.15 and 35.15 and counting the number of events. This gives a back ground noise near the $32 \mathrm{amu}$ value of $1.310^{-5}$ ions/amu. As the cumulated window width for the $(\mathrm{TiO})^{2+}$ peaks is $0.65 \mathrm{amu}$, the influence of the background noise could be considered as negligible ( $\leq 10$ at.ppm). 


\section{RESULTS}

\section{Two-phase alloys}

The compositions of the two alloys we studied are given in table 1.

TABLE 1 - Composition (at.\% and at. ppm) of the two Alloys $\mathrm{Ti}_{52} \mathrm{Al}_{48}$ and $\mathrm{Ti}_{54} \mathrm{Al}_{46}$ determined by Chemical Analysis

\begin{tabular}{|c|c|c|}
\hline & $\mathrm{Ti}_{52} \mathrm{Al}_{48}$ & $\mathrm{Ti}_{54} \mathrm{Al}_{46}$ \\
\hline Aluminium & $47.9 \% \pm 0,4 \%$ & $46 \% \pm 0,4 \%$ \\
\hline Titanium & $51.8 \% \pm 0,4 \%$ & $53.7 \% \pm 0,4 \%$ \\
\hline Oxygen & $2290 \pm 230 \mathrm{ppm}$ & $2500 \pm 250 \mathrm{ppm}$ \\
\hline Carbon & $560 \pm 30 \mathrm{ppm}$ & $540 \pm 30 \mathrm{ppm}$ \\
\hline
\end{tabular}

The oxygen concentration in the two phase $\alpha_{2}$ and $\gamma$ determined by atom probe analysis is reported in table 2 for the two alloys $\mathrm{Ti}_{52} \mathrm{Al}_{48}$ and $\mathrm{Ti}_{54} \mathrm{Al}_{46}$ in the as cast state, and for the $\mathrm{Ti}_{54} \mathrm{Al}_{46}$ alloy heat treated $168 \mathrm{H}$ at $1000^{\circ} \mathrm{C}$. Atomic fractions $(\approx$ volume fractions since the volume occupied by an atom in the unit cell is nearly the same for both phases $\alpha_{2}$ and $\gamma$ ) are calculated by means of the classical lever rule : $F \alpha_{2}=\left(C_{N}-C_{\gamma}\right) /\left(C \alpha_{2}-C_{\gamma}\right)$, where $C_{N}$ is the oxygen concentration of the alloy determined by the chemical analysis. $C_{\gamma}$ and $\mathrm{C} \alpha_{2}$ are the oxygen concentrations in the $\gamma$ and $\alpha_{2}$ phase as determined by the atom-probe analysis. These volume fractions are consistent with those estimated from TEM observations. This result is a good indication of the reliability of our oxygen concentration measurements.

TABLE 2 - oxygen concentration in $\alpha_{2}$ and $\gamma$ phases and volume fractions $F_{v} \alpha_{2}$ of the $\alpha_{2}$ phase deduced from Atom-Probe Analysis and TEM observations for the two Alloys $\mathrm{Ti}_{52} \mathrm{Al}_{48}$ and $\mathrm{Ti}_{54} \mathrm{Al}_{46}$.

\begin{tabular}{|l|c|c|c|c|c|c|}
\hline & \multicolumn{2}{|c|}{$\mathrm{Ti}_{52} \mathrm{Al}_{48}$ as cast } & \multicolumn{2}{c|}{$\mathrm{Ti}_{54} \mathrm{Al}_{46}$ as cast } & \multicolumn{2}{c|}{$\mathrm{Ti}_{54} \mathrm{Al}_{46} 1000^{\circ} \mathrm{C} 168 \mathrm{H}$} \\
\hline & $\alpha_{2}$ & $\gamma$ & $\alpha_{2}$ & $\gamma$ & $\alpha_{2}$ & $\gamma$ \\
\hline Oxygen at. ppm & $21600 \pm 2100$ & $230 \pm 70$ & $8100 \pm 700$ & $200 \pm 100$ & $15000 \pm 900$ & $180 \pm 100$ \\
\hline $\bar{F}_{\mathrm{v}} \alpha_{2}$ AP & $10 \pm 3 \%$ & \multicolumn{2}{|c|}{$29 \pm 7 \%$} & $16 \pm 4 \%$ \\
\hline $\mathrm{F}_{\mathrm{v}} \alpha_{2}$ TEM & \multicolumn{2}{|c|}{$30 \pm 5 \%$} & \multicolumn{2}{|c|}{$30 \pm 5 \%$} & $17 \pm 5 \%$ \\
\hline
\end{tabular}

The main observations we can made from these results are : the preferential location of oxygen in the $\alpha_{2}$ phase as previously mentioned, and the remarkably low oxygen level in $\gamma$ phase. Moreover the oxygen concentrations observed in the $\gamma$ phase are nearly identical $(\approx 200 \mathrm{ppm})$ in both alloys while the volume fractions of the $\alpha_{2}$ phase are different. This leads to the conclusion that the maximum solubility of oxygen in $\gamma$ is close to the observed value.

\section{Single-phase alloys}

In order to check this idea (maximum solubility of oxygen in $\gamma \sim 150-300$ ppm taking into account statistical fluctuations as given in table 4), we analysed single phase alloys with different oxygen contents (high purity, 1 at $\%$ and 2 at $\%$ oxygen). The overall composition of these alloys as determined by chemical analysis is given in table 3.

The alloys are heat treated $48 \mathrm{H}$ at $1300^{\circ} \mathrm{C}$ then quenched. The oxygen concentrations measured by atom probe analysis are given in table 4. 
TABLE 3 - Overall composition (at.\% and at. ppm) of the single phase alloys $\mathrm{Ti}_{48} \mathrm{Al}_{52}$ determined by Chemical Analysis

\begin{tabular}{|c|c|c|c|}
\hline & $\mathrm{Ti}_{48} \mathrm{Al}_{52}$ & $\left(\mathrm{Ti}_{48} \mathrm{Al}_{52}\right)_{99} \mathrm{O}_{1}$ & $\left(\mathrm{Ti}_{48} \mathrm{Al}_{52}\right)_{98} \mathrm{O}_{2}$ \\
\hline Aluminium & $52.3 \%$ & 51.7 & \\
\hline Titanium & $47.5 \%$ & 47.5 & \\
\hline Oxygen & $1650 \mathrm{ppm}$ & $6880 \mathrm{ppm}$ & $1,97 \mathrm{at} . \%$ \\
\hline Carbon & $340 \mathrm{ppm}$ & $430 \mathrm{ppm}$ & $580 \mathrm{ppm}$ \\
\hline
\end{tabular}

TABLE 4 - Oxygen concentrations in the $\gamma$ phase of single-phase $\mathrm{Ti}_{48} \mathrm{Al}_{52}$ alloys, as determined by AP.

\begin{tabular}{|c|c|c|c|}
\hline & $\mathrm{Ti}_{48} \mathrm{Al}_{52}$ & $\left(\mathrm{Ti}_{48} \mathrm{Al}_{52}\right)_{99} \mathrm{O}_{1}$ & $\left(\mathrm{Ti}_{48} \mathrm{Al}_{52}\right)_{98} \mathrm{O}_{2}$ \\
\hline Oxygen (at. ppm) & $300 \pm 300$ & $310 \pm 150$ & $180 \pm 100$ \\
\hline
\end{tabular}

In spite of the unavoidable statistical fluctuations due to the very small number of oxygen atom collected in these early experiments, these results clearly demonstrate that the oxygen level in the matrix of these single-phase alloys is very similar to that we found in the $\gamma$ phase of the two-phase alloys. In fact, in these oxygen charged single phase alloys, oxide precipitates were observed [11] [12]. It is interesting and statistically more representative to compare the cumulated results we obtained in the $\gamma$ phase of two-phase alloys to that of single-phase alloys :

single phase alloys, oxygen concentration $(160 \pm 80)$ at. ppm.

two-phase alloys, oxygen concentration $(220 \pm 70)$ at. ppm.

these results were obtained over about 300000 ions, the error bars are taken as two standard deviations.

\section{CONCLUSION}

The oxygen concentration in the $\gamma$ matrix of the binary alloys we studied is remarkably independent of the volume fraction of $\alpha_{2}$ phase. This oxygen concentration is very similar to the oxygen concentration we measured in the $\gamma$ single-phase alloys. Moreover, this oxygen level is insensitive to the nominal oxygen composition of the alloys. These two findings indicate that the oxygen concentrations we measured in the $\gamma$ phase should be very close to the maximum solubility of oxygen in this phase. This maximum solubility can be evaluated to stand in the range $(300 \pm 150) \mathrm{ppm}$ for material heat treated at temperatures of about $1000^{\circ} \mathrm{C}$. As a result, the higher ductility observed on two-phase alloys can no longer be explained by the simple purification effect of the $\gamma$ matrix due to the $\alpha_{2}$ phase. Two others explanations have to be considered. The first one, which has been previously mentioned, is the structural effect of the lamellar microstructure. The second one is a precipitation effect due to oxygen. As the maximum solubility of oxygen in $\gamma$ is much lower than the impurity level in these alloys (even for very high purity alloy), oxygen in excess leads to the precipitation of undesirable phases (oxides) in single phase $\gamma$ TiAl aluminium rich alloys. This excess is absorbed in the $\alpha_{2}$ phase for two phase titanium rich alloys. Therefore the better ductility observed for $\alpha_{2}+\gamma$ alloys could be due as well, to the absence of oxides in these alloys (which in fact are not observed). It should also be noticed that this explanation is not inconsistent with the possible structural effect of the lamellar structure.

\section{Acknowledgements}

This work was conducted with a financial support of SNECMA and TURBOMECA and for atom probe studies under a contract of the French Ministry of Defense, DRET $N^{\circ} 92 / 115$. 


\section{References}

[1] MENAND A., CHAMBRELAND S., MARTIN C., J. de Physique, C2, 47, (1986) 197

[2] MENAND A., HADJADJ L., BLAVETTE D., Proc. of "6th world conference on Titanium" Les Editions de Physique, (1988), 1577

[3] KAWABATA T., TAMURA T. and IZUMI O., Proc. Mat. Res. Soc. Symp. on "High Temperature Ordered Intermetallic Alloys", Boston, MRS, 1989, 133, 329.

[4] KIM Y. W. , JOM, 41 (7) (1989), 24.

[5] KIM Y, W. and FROES F. H., "High temperature Aluminidedes and Intermetallics" Edited by B. H. WHANG, C.T. LIU, D.P. POPE and J.O. STIEGLER, The Minerals, Metals and Materials Society, 1990. [6] HUANG S.C. and HALL E.L., Proc. Mat. Res. Soc. Symp. on "High Temperature Ordered Intermetallic Alloys", Boston, MRS, 133 (1989), 373

[7] UEMORI R., HANAMURA T. and MORIKAWA H., Scripta Met., 26, (1992), 969

[8] DENQUIN A., NAKA S., HUGUET A. and MENAND A., Scripta Met., 28, (1993)

[9] MENAND A., HADJADJ L. and VASSEL A., Scripta Met.,_21,(1987), 1295

[10] DECONIHOUT B., MENAND A., BOUET M. and SARRAU J. M., Surface Science, 266 (1992) 523-528

[11] HUG G., Rapport technique ONERA n RT 28/7228M

[12] HUG G., BLANCHE G., JAOUEN M., and FLANK A.M., 27th Meeting of the Microbeam Analysis Society,

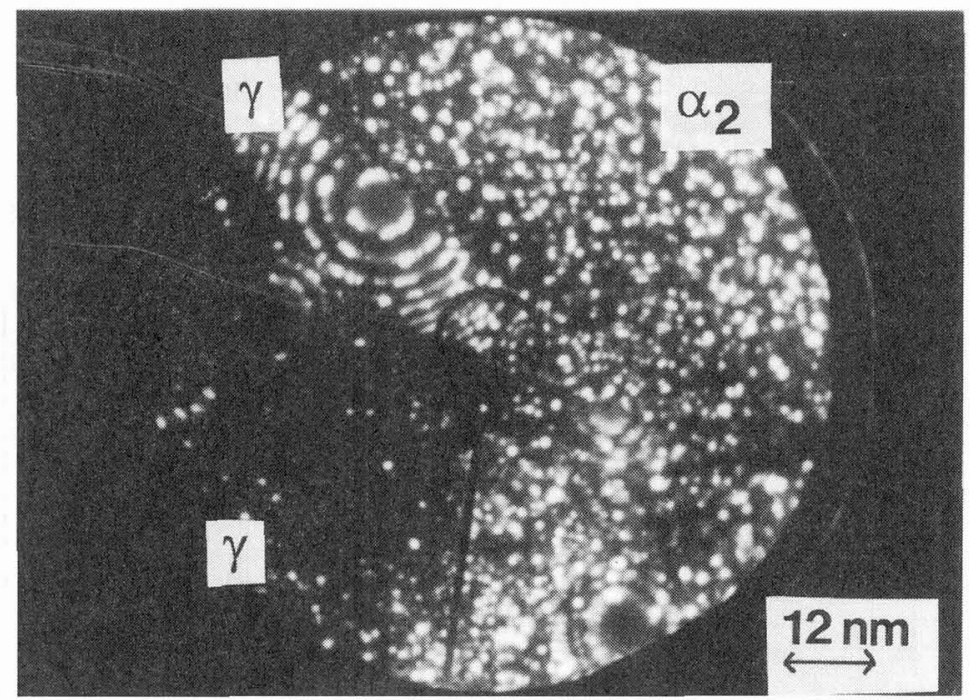

Figure 1 FIM image of a two phase $\alpha_{2}+\gamma$ alloy. An interface between two lamellae $\alpha_{2}$ and $\gamma$ is visible as well as a twin boundary $\gamma-\gamma$. 
(a)

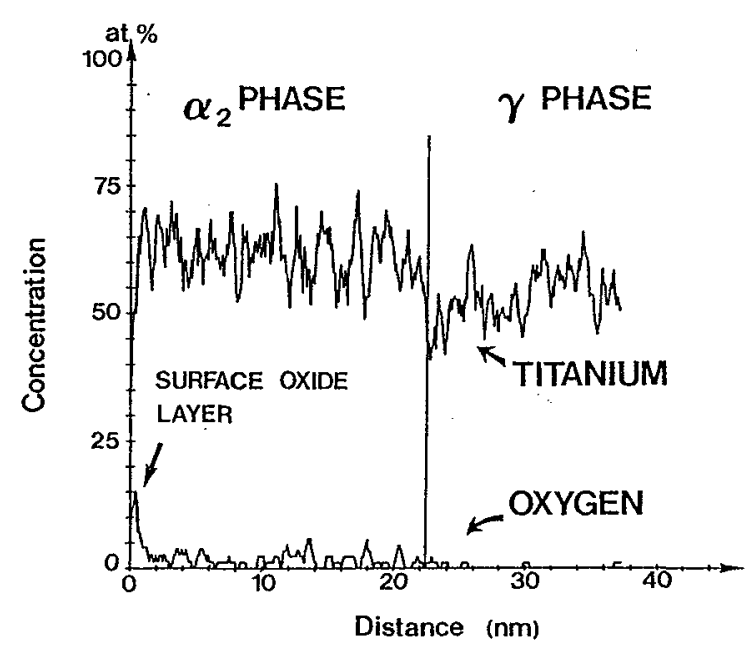

(b)

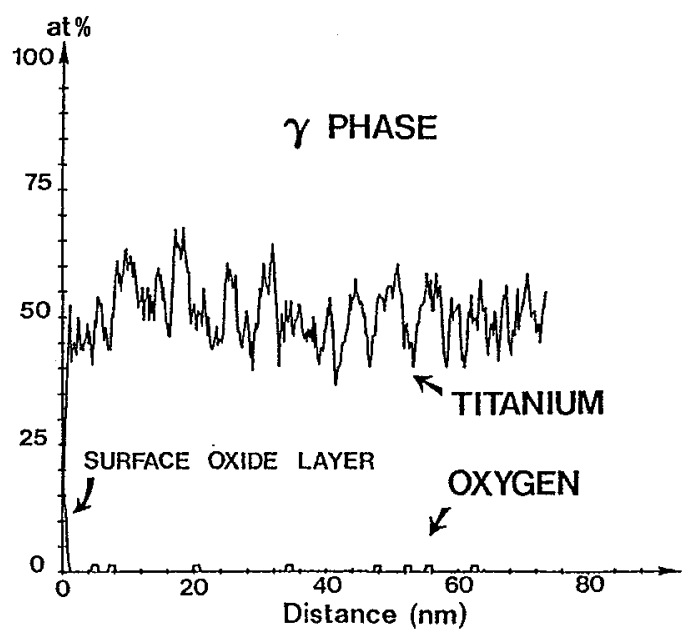

Figure 2 This concentration profiles show the presence of an oxide layer which forms at the surface of the tip for both phases $\alpha_{2}$ (a) and $\gamma$ (b). This figure (a) also exhibits the preferential location of oxygen in the $\alpha_{2}$ phase .
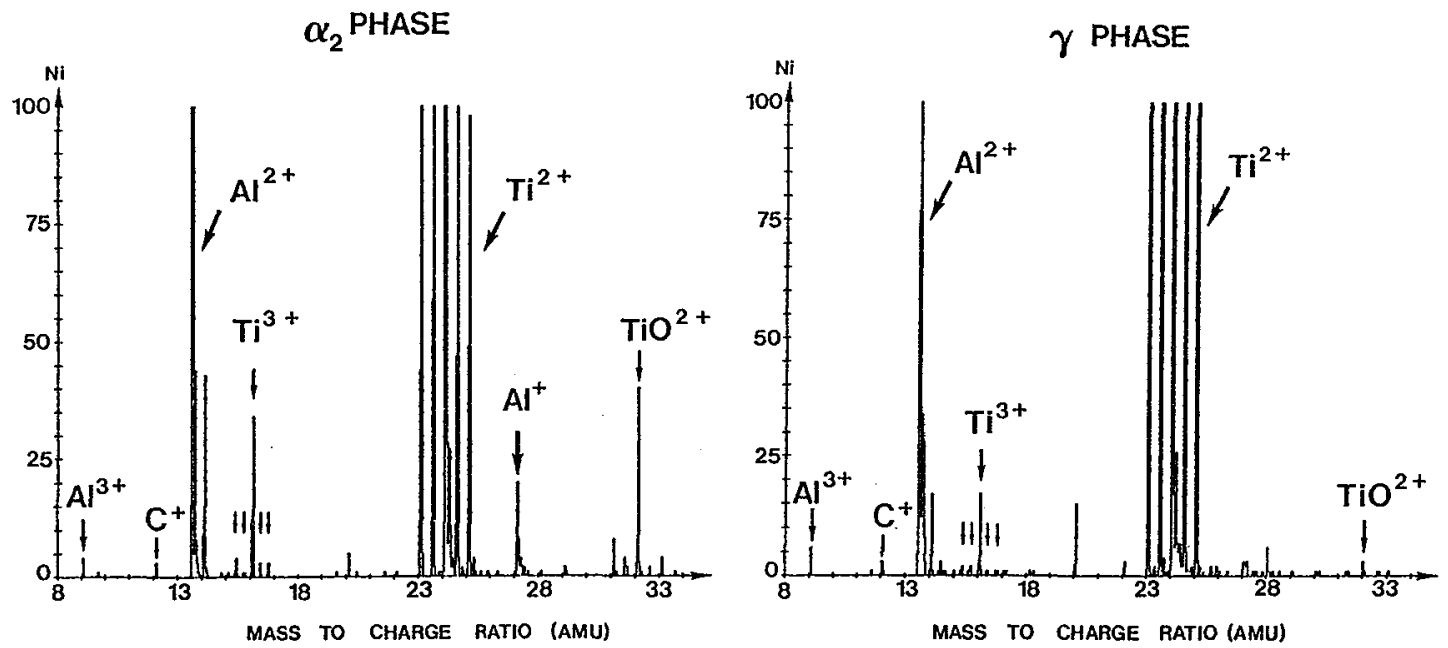

Figure 3 High resolution atom probe mass spectra related to $\alpha_{2}$ and $\gamma$ phases. 